\title{
Evaluation of liver function before and during therapy
}

\author{
Matthias Buechter, Guido Gerken \\ Department of Gastroenterology and Hepatology, University Hospital Essen, University of Duisburg-Essen, Essen 45147, \\ Germany.
}

Correspondence to: Dr. Matthias Buechter, Associate Professor of Medicine, University Hospital Essen, Hufelandstr. 55, Essen 45147, Germany. E-mail: matthias.buechter@uk-essen.de

How to cite this article: Buechter M, Gerken G. Evaluation of liver function before and during therapy. Hepatoma Res 2021;7:48. https://dx.doi.org/10.20517/2394-5079.2021.76

Received: 8 Jun 2021 Accepted: 10 Jun 2021 First online: 17 Jun 2021

Academic Editor: Guang-Wen Cao Copy Editor: Yue-Yue Zhang Production Editor: Yue-Yue Zhang

Hepatocellular carcinoma (HCC) is a major cause of morbidity and mortality worldwide and the fastestrising course of cancer-related death in the United States. In most instances, HCC emerges as a sequel to ongoing chronic hepatitis, occurring after the development of liver cirrhosis irrespective of its underlying etiology. However, patients with hepatitis b (HBV)- or hepatitis c virus-induced cirrhosis are at the highest risk for the development of HCC, with an annual incidence ranging from $0.5 \%$ to $10 \%^{[1-3]}$. Non-alcoholic fatty liver disease (NAFLD), associated with diabetes mellitus and obesity, is now the most common liver disease and a major risk factor for HCC in developed countries. Although HCC can occur due to chronic HBV infection or NAFLD in the absence of cirrhosis (non-cirrhotic HCC), > 90\% of these patients also suffer from cirrhotic liver disease ${ }^{[4,5]}$.

Over the last decades various treatment modalities have become available depending on the stage of HCC. Nowadays, the management of HCC involves a personalized decision-making process, taking into account not only the burden and extent of HCC but also patient co-morbidities and performance status. The severity of liver dysfunction plays a crucial role in this regard, since most treatments for HCC can exacerbate underlying liver disease, potentially leading to post-interventional liver failure ${ }^{[6,7]}$.

Therapeutic advances include surgical procedures (liver resection and liver transplantation) and locoregional [radiofrequency ablation (RFA), transarterial chemoembolization (TACE), and 
radioembolization] and systemic drug therapies (sorafenib and atezolizumab plus bevacizumab) in unresectable or advanced stages. These different approaches can be combined to achieve the best patients' outcome. In early or intermediate stages, potentially curative therapies such as RFA, liver resection, or liver transplantation should be the first-line treatments when possible ${ }^{[8]}$.

Individually, patient-focused planning should ensure a considerable amount of safety with regard to therapeutic interventions. Liver function, however, is the key factor in the decision process to choose the adequate therapeutic modality since a drop below the critical functional reserve leads to subsequent liver failure, which is associated with poor prognosis and remains the major cause of post-interventional mortality. Therefore, close monitoring of liver function before, during, and after HCC therapy is mandatory ${ }^{[9,10]}$.

Determination of liver function is usually carried out by the use of conventional blood parameters, such as enzymes, albumin, bilirubin, or INR, as well as scoring systems derived from those values [e.g., Child-Pugh Score (CPS), Albumin-Bilirubin (ALBI) score, or Model of End-Stage Liver Disease score]. However, these parameters do not seem to be reliable enough since they are not exclusively liver-specific and are biased by a variety of other factors such as deficiencies, iatrogenic substitution, and biological half-life. Remarkably, these markers are frequently compensated and within normal ranges even when advanced liver fibrosis or even cirrhosis is already present ${ }^{[1,12]}$.

Recently, the dynamic measurement of the enzymatic liver function by the Liver Maximum Capacity (LiMAx) breath test has been introduced as a robust technique to determine dynamic liver function based on the specific hepatic cytochrome $\mathrm{P} 4501 \mathrm{~A} 2$ metabolism of an intravenously injected substance $\left({ }^{13} \mathrm{C}\right.$ methacetin). ${ }^{13} \mathrm{C}$-methacetin is immediately demethylated into acetaminophen and ${ }^{13} \mathrm{CO}_{2}$ in hepatocytes: the latter is subsequently exhaled, leading to an increase of ${ }^{13} \mathrm{CO}_{2}$ concentration in air. Prior to substrate injection, the individual baseline ratio of ${ }^{13} \mathrm{CO}_{2} /{ }^{12} \mathrm{CO}_{2}$ concentration is measured, and thus liver function capacity can be calculated from the analysis of the ${ }^{13} \mathrm{CO}_{2} /{ }^{12} \mathrm{CO}_{2}$ ratio ${ }^{[1,13]}$ [Figure 1].

Liver resection is the most effective available therapy for patients with HCC. The accurate selection of patients for surgery requires determination of technical resectability and the risk of recurrence, as well as the assessment of liver function and functional reserve to avoid postoperative liver failure. Several studies have shown the effectiveness and reliability of the LiMAx test to evaluate liver function pre- and postoperatively ${ }^{[14-16]}$. On the basis of these findings, Stockmann et a ${ }^{[11]}$. developed a decision tree algorithm combining volume planning (CT scan) together with a measurement of preoperative liver function capacity obtained by using the LiMAx test [Figure 2]. Hereby, preoperative evaluation and postoperative outcome was significantly improved in patients undergoing liver resection for $\mathrm{HCC}^{[11,15-17]}$.

Locoregional therapies such as TACE or radioablation are important therapies for HCC in cirrhosis. These interventions are associated with the risk of deteriorating liver function, particularly in patients with advanced cirrhosis. However, there is no widely accepted standardization for the periinterventional risk assessment, which is usually carried out by single center protocols according to the local expertise. Current investigations could demonstrate reliable and reproducible results for LiMAx measurements in detecting changes in liver function, even with regard to modulations caused by superselective procedures. Enzymatic liver function measured by the LiMAx test was superior to biochemical parameters and conventional scoring systems such as CPS or ALBI score, which were less specific in providing sufficient information on cellular dysfunction ${ }^{[18,19]}$. 


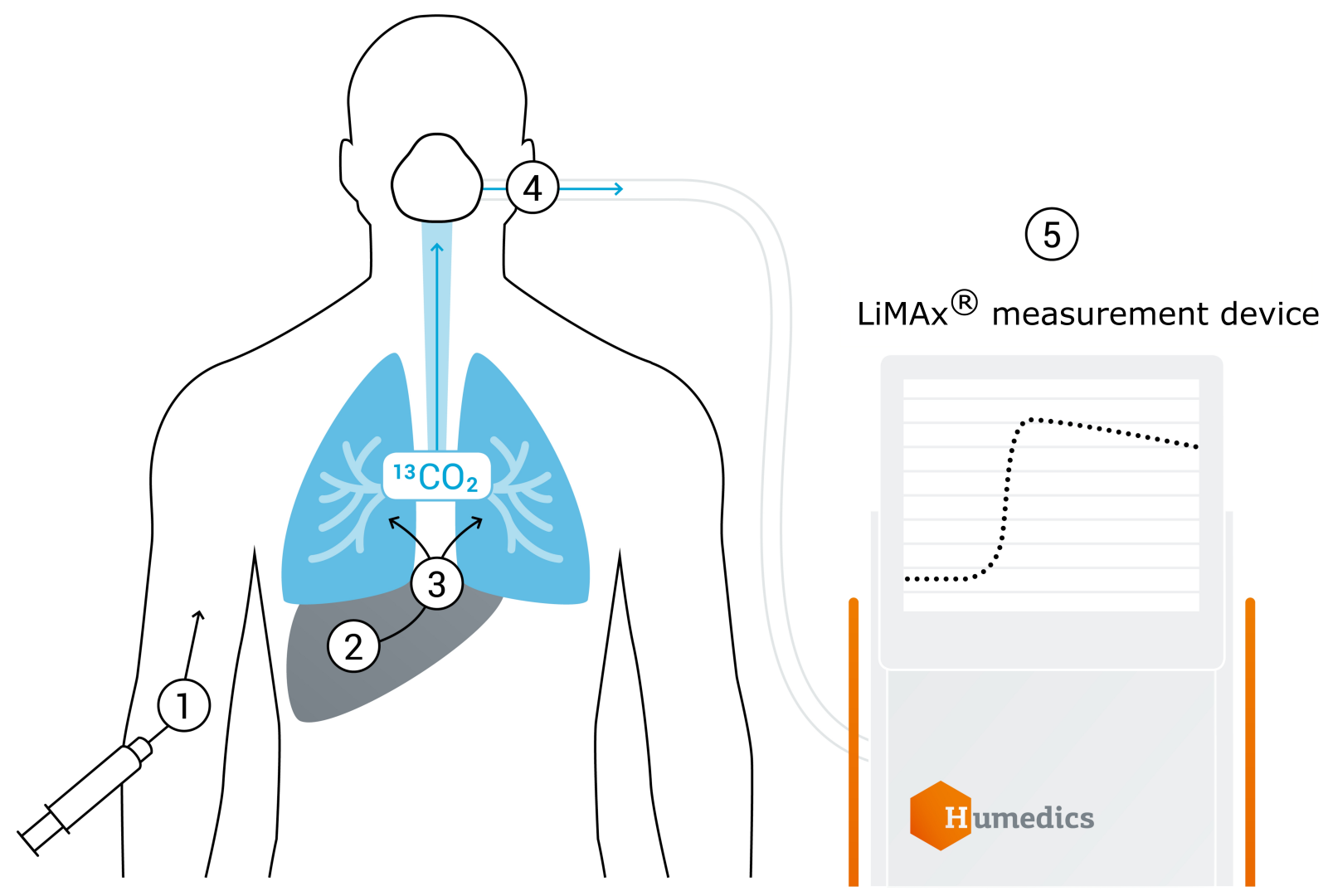

\section{(1) Intravenous injection of ${ }^{13} \mathrm{C}$-methacetin solution}

(2) Metabolization Paracetamol $+{ }^{13} \mathrm{CO}_{2}$

(3) Venous transport to lung

(4) Exhalation

(5) Measurement and calculation

Figure 1. Schema of the LiMAx test.

In conclusion, various modalities for the treatment of patients with HCC have become available over the last decades. Individually, patient-focused planning should ensure a considerable amount of safety before, during, and after HCC therapy with regard to pretherapeutic selection and posttherapeutic surveillance, especially to prevent and detect deterioration of liver function. Apart from conventional clinical and laboratory parameters used for this purpose, the LiMAx test offers valuable additional information, enhancing the safety of treatment procedures for HCC. 


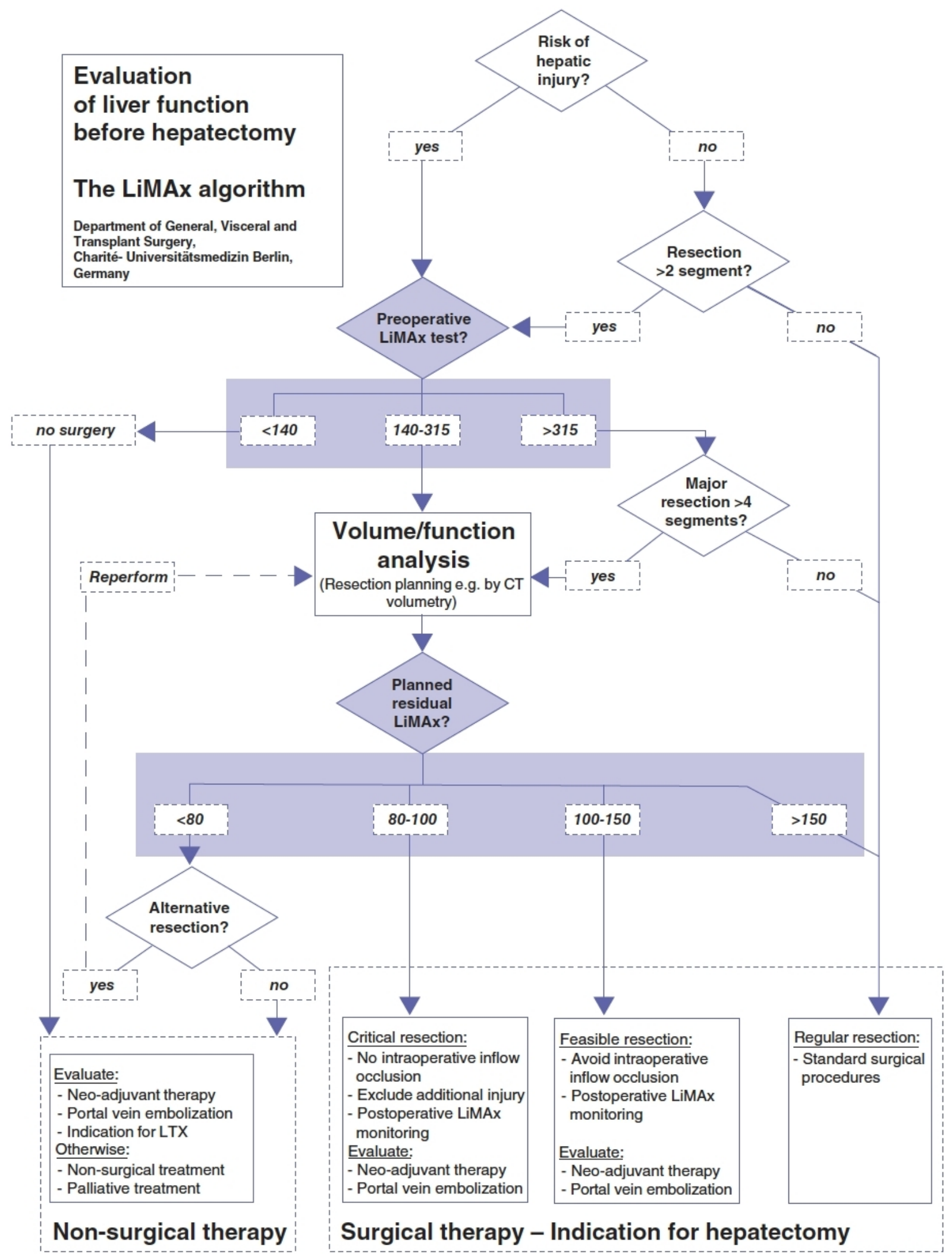

Figure 2. The LiMAx algorithm: a clinical decision tree for preoperative evaluation before hepatectomy. LTX: Liver transplant; CT: computed tomography. 


\section{DECLARATIONS}

\section{Acknowledgments}

We thank Prof. Martin Stockmann and Alexander Helmke (Humedics) for the approval to use their figures.

\section{Authors' contributions}

Wrote the manuscript: Buechter M

Conceptualized and corrected the manuscript: Gerken G

\section{Availability of data and materials}

Not applicable.

\section{Financial support and sponsorship}

None.

\section{Conflicts of interest}

Both authors declared that there are no conflicts of interest.

\section{Ethical approval and consent to participate}

Not applicable.

\section{Consent for publication}

Not applicable.

\section{Copyright}

(c) The Author(s) 2021.

\section{REFERENCES}

1. Kulik L, El-Serag HB. Epidemiology and management of hepatocellular carcinoma. Gastroenterology 2019;156:477-91.e1. DOI PubMed PMC

2. Yang JD, Hainaut P, Gores GJ, et al. A global view of hepatocellular carcinoma: trends, risk, prevention and management. Nat Rev Gastroenterol Hepatol 2019;16:589-604. DOI PubMed PMC

3. Yang JD, Mohamed HA, Cvinar JL, et al. Diabetes mellitus heightens the risk of hepatocellular carcinoma except in patients with hepatitis C cirrhosis. Am J Gastroenterol 2016;111:1573-80. DOI PubMed PMC

4. Younossi ZM, Blissett D, Blissett R, et al. The economic and clinical burden of nonalcoholic fatty liver disease in the United States and Europe. Hepatology 2016;64:1577-86. DOI PubMed

5. Chayanupatkul M, Omino R, Mittal S, et al. Hepatocellular carcinoma in the absence of cirrhosis in patients with chronic hepatitis B virus infection. J Hepatol 2017;66:355-362. DOI PubMed

6. Couri T, Pillai A. Goals and targets for personalized therapy for HCC. Hepatol Int 2019;13:125-37. DOI PubMed

7. Serper M, Taddei TH, Mehta R, et al. Association of provider specialty and multidisciplinary care with hepatocellular carcinoma treatment and mortality. Gastroenterology 2017;152:1954-64. DOI PubMed PMC

8. Heimbach JK. Overview of the updated AASLD guidelines for the management of HCC. Gastroenterol Hepatol 2017;13:751-3. PubMed PMC

9. Schneider PD. Preoperative assessment of liver function. Surg Clin North Am 2004;84:355-73. DOI PubMed

10. Farges O, Malassagne B, Flejou JF, et al. Risk of major liver resection in patients with underlying chronic liver disease: a reappraisal. Ann Surg 1999;229:210-5. DOI PubMed PMC

11. Stockmann M, Lock JF, Malinowski M, et al. The LiMAx test: a new liver function test for predicting postoperative outcome in liver surgery. HPB (Oxford) 2010;12:139-46. DOI PubMed PMC

12. Buechter M, Thimm J, Baba HA, et al. Liver maximum capacity: a novel test to accurately diagnose different stages of liver fibrosis. Digestion 2019;100:45-54. DOI PubMed

13. Buechter M, Kersting S, Gerken G, et al. Enzymatic liver function measured by LiMAx - a reliable diagnostic and prognostic tool in chronic liver disease. Sci Rep 2019;9:13577. DOI PubMed PMC

14. Anger F, Klein I, Löb S, et al. Preoperative liver function guiding HCC resection in normal and cirrhotic liver. Visc Med 2021;37:94101. DOI PubMed PMC

15. Blüthner E, Jara M, Shrestha R, et al. The predictive value of future liver remnant function after liver resection for HCC in noncirrhotic and cirrhotic patients. HPB (Oxford) 2019;21:912-22. DOI PubMed 
16. Stockmann M, Vondran FWR, Fahrner R, et al. Randomized clinical trial comparing liver resection with and without perioperative assessment of liver function. BJS Open 2018;2:301-9. DOI PubMed PMC

17. Stockmann M, Lock JF, Riecke B, et al. Prediction of postoperative outcome after hepatectomy with a new bedside test for maximal liver function capacity. Ann Surg 2009;250:119-25. DOI PubMed

18. Barzakova ES, Schulze-Hagen M, Zimmermann M, et al. Monitoring liver function of patients undergoing transarterial chemoembolization (TACE) by a 13C breath test (LiMAx). Cardiovasc Intervent Radiol 2019;42:1702-8. DOI PubMed

19. Reichert MC, Massmann A, Schulz A, et al. Volume-function analysis (LiMAx Test) in patients with HCC and cirrhosis undergoing TACE-A feasibility study. Dig Dis Sci 2020. DOI PubMed 